Annales Geophysicae (2002) 20: 781-794 (c) European Geophysical Society 2002

\title{
Ground-based observations of the auroral zone and polar cap ionospheric responses to dayside transient reconnection
}

\author{
J. A. Davies ${ }^{1}$, T. K. Yeoman ${ }^{1}$, I. J. Rae ${ }^{1}$, , S. E. Milan ${ }^{1}$, M. Lester ${ }^{1}$, M. Lockwood ${ }^{2}$, and A. McWilliams ${ }^{1}$ \\ ${ }^{1}$ Department of Physics and Astronomy, University of Leicester, Leicester, UK \\ ${ }^{2}$ Rutherford Appleton Laboratory, Oxfordshire, UK/Department of Physics and Astronomy, Southampton University, \\ Southampton, UK \\ * now at Department of Physics, University of Alberta, Edmonton, Alberta, Canada
}

Received: 20 December 2001 - Accepted: 19 February 2002

\begin{abstract}
Observations from the EISCAT VHF incoherent scatter radar system in northern Norway, during a run of the common programme CP-4, reveal a series of polewardpropagating F-region electron density enhancements in the pre-noon sector on 23 November 1999 . These plasma density features, which are observed under conditions of a strongly southward interplanetary magnetic field, exhibit a recurrence rate of under $10 \mathrm{~min}$ and appear to emanate from the vicinity of the open/closed field-line boundary from where they travel into the polar cap; this is suggestive of their being an ionospheric response to transient reconnection at the dayside magnetopause (flux transfer events). Simultaneous with the density structures detected by the VHF radar, polewardmoving radar auroral forms (PMRAFs) are observed by the Finland HF coherent scatter radar. It is thought that PMRAFs, which are commonly observed near local noon by HF radars, are also related to flux transfer events, although the specific mechanism for the generation of the field-aligned irregularities within such features is not well understood. The HF observations suggest, that for much of their existence, the PMRAFs trace fossil signatures of transient reconnection rather than revealing the footprint of active reconnection itself; this is evidenced not least by the fact that the PMRAFs become narrower in spectral width as they evolve away from the region of more classical, broad cusp scatter in which they originate. Interpretation of the HF observations with reference to the plasma parameters diagnosed by the incoherent scatter radar suggests that as the PMRAFs migrate away from the reconnection site and across the polar cap, entrained in the ambient antisunward flow, the irregularities therein are generated by the presence of gradients in the electron density, with these gradients having been formed through structuring of the ionosphere in the cusp region in response to transient reconnection.
\end{abstract}

Correspondence to: J. A. Davies (jaq@ion.le.ac.uk)
Key words. Magnetospheric physics (magnetosphere-ionosphere interaction) - ionosphere (ionospheric irregularities; plasma density and temperature)

\section{Introduction}

The first observational evidence for impulsive, transient reconnection at the dayside magnetopause was presented by Haerendel et al. (1978), based on HEOS-2 satellite measurements, and Russell and Elphic (1978; 1979), using observations from the ISEE-1 and -2 spacecraft. The latter authors coined the term flux transfer event (FTE) to describe an individual reconnection pulse. Subsequent investigation of spacecraft observations near the magnetopause has revealed that FTEs - generally identified by a characteristic bipolar signature in the boundary-normal component of the magnetic field, accompanied by an increase in the total field magnitude - occur most commonly under conditions when the $Z$ component of the magnetic field measured in the interplanetary medium is southward (e.g. Rijnbeek et al., 1984; Kuo et al., 1995; Kawano and Russell, 1997) and have a mean recurrence rate of 7 to 8 min (Rijnbeek et al., 1984; Lockwood and Wild, 1993; Kuo et al., 1995). Even though there is substantial evidence supporting the idea that FTEs are the signature of transient reconnection, there is still considerable debate concerning the relative contributions of bursty and quasi-steady state reconnection to dayside coupling of the interplanetary and terrestrial magnetic fields.

Signatures of reconnection at the magnetopause map into spatially confined regions of the dayside ionosphere. It was, however, several years after their initial identification by spacecraft before such ground-based signatures of FTEs were reported, the first being by van Eyken et al. (1984) and Goertz et al. (1985). Since this early work, a multi- 


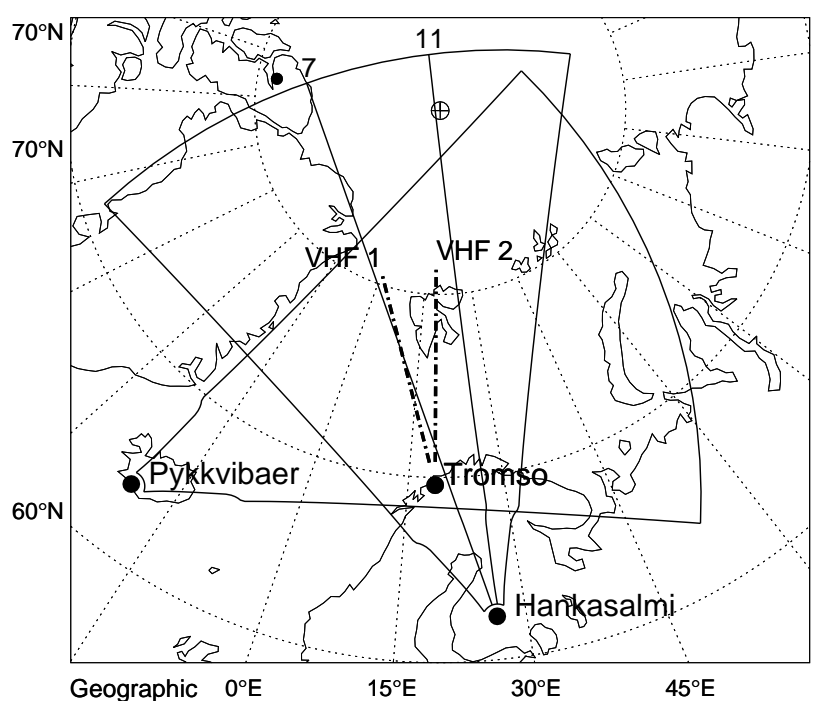

Fig. 1. Map depicting the fields-of-view of the CUTLASS Finland and Iceland East radars. Beams 7 and 11 of the Finland radar are indicated explicitly, as solid lines. In addition, the two beams of the EISCAT VHF radar are illustrated as thick broken lines. The small filled circle and the cross within a circle represent the positions of the magnetic and geographic poles, respectively, whereas larger filled circles indicate the locations of the radars themselves.

tude of further observations of the ground-based signatures of impulsive reconnection have been published. These include many observations by the HF coherent scatter radars of the Super Dual Auroral Radar Network (SuperDARN) of dayside transients, which generally exhibit an antisunward motion. Dependant on their exact characteristics, and crucially, the parameter in which they are identified, these ionospheric transients have been termed flow channel events (FCEs) (Pinnock et al., 1993; 1995; Neudegg et al., 1999; 2000), pulsed ionospheric flows (PIFs) (Provan et al., 1998; Provan and Yeoman, 1999; McWilliams et al., 2000) or poleward-moving radar auroral forms (PMRAFs) (Wild et al., 2001). However, it has become increasingly evident that these three so-called forms of dayside transients are in fact very much related, and in some cases actually describe the same phenomena; this is discussed by Wild et al. (2001) and in more detail later in the present paper. Such dayside transients observed by HF radar have been found to exhibit a repetition rate comparable to that of FTEs observed at the magnetopause (Provan et al., 1998; McWilliams et al., 2000) and have been observed in conjunction with cusp ion steps detected by low altitude spacecraft by Yeoman et al. (1997) and optical signatures termed poleward-moving auroral forms (PMAFs) (Milan et al., 1999; 2000); both cusp ion steps (e.g. Lockwood and Smith, 1992; 1994) and PMAFs (e.g. Sandholt et al., 1992; Fasel, 1995) are also acknowledged signatures of FTEs. Although it is thought that these dayside HF transients are indeed a radar signature of impulsive reconnection, only Neudegg et al. $(1999 ; 2000)$ and Wild et al. (2001) have demonstrated this definitively. Neudegg et al. $(1999 ; 2000)$ present such transients observed in conjunction with the characteristic magnetic signatures of FTEs detected conjugately at the magnetopause by the Equator-S spacecraft, while Wild et al. (2001) report their observation in association with conjugate magnetopause signatures detected by the recently launched Cluster satellites.

At F-region altitudes, HF coherent scatter is from fieldaligned irregularities created by either the gradient drift instability or the current convective instability; a comprehensive description of these instability mechanisms is documented by Tsunoda (1988) and references therein. The gradient drift or $\boldsymbol{E} \times \boldsymbol{B}$ instability is generated in the presence of a gradient in electron density in a direction perpendicular to the magnetic field direction $\boldsymbol{B}$, with an applied electric field $\boldsymbol{E}$ with a component along that gradient. The current convective instability is similar in nature to the gradient drift instability but grows in the presence of a field-aligned current. It is well known that the motion of F-region irregularities is determined by the ambient plasma convection (see Davies et al., 2000, and references therein).

The instability mechanism responsible for the generation of irregularities within the HF transients observed on the dayside in response to FTEs, and hence, their exact relationship to the processes of particle precipitation and electric field modification arising in the cusp region due to reconnection at the magnetopause, is not well understood. Yet this is critical in unlocking the full potential of ionospheric measurements as diagnostics of magnetospheric processes. In the current work, EISCAT VHF observations of plasma conditions in the vicinity of such HF features, the latter detected by the CUTLASS Finland radar of the SuperDARN network, provides an ideal opportunity to help resolve this question.

\section{Experimental arrangement}

An extended run of the EISCAT VHF common programme4 (CP-4) mode commenced at 10:00 universal time (UT) on 22 November 1999 and continued until 16:00 UT on 24 November 1999. In CP-4, the VHF incoherent scatter radar at Troms $\varnothing$ in northern Norway (e.g. Rishbeth and van Eyken, 1993) is operated in a split-beam mode with one beam (beam 2) directed along the radar boresight, which corresponds to a geographic azimuth of $359.5^{\circ}$, and the other (beam 1) phased $14.5^{\circ}$ west to an azimuth of $345.0^{\circ}$; both beams are at an elevation of $30^{\circ}$. Long pulse and power profile codes are transmitted, the former providing estimates of plasma concentration, ion and electron temperatures and line-of-sight ion velocity over 20 gates along each beam, with a total altitude coverage of some 280 to $1050 \mathrm{~km}$. The power profile pulse scheme yields raw electron density measurements at a range resolution of $4.5 \mathrm{~km}$, over 83 gates from 80 to $280 \mathrm{~km}$ altitude. Observations from both the long pulse and power profile codes from the November 1999 run of CP4 have been analysed at a temporal resolution of $10 \mathrm{~s}$.

During the CP-4 run, both the Finland and Iceland East radars of the CUTLASS HF coherent scatter system, situated 



Fig. 2. Interplanetary magnetic field (IMF) observations from the ACE and Wind spacecraft, between 06:45 and 09:45 UT on 23 November 1999. Panels, from the top, illustrate the $X, Y$ and $Z$ components of the IMF in geocentric solar magnetic (GSM) coordinates for both the ACE (thick line) and Wind spacecraft (thin line). Data are corrected to account for the time delay from the spacecraft to the subsolar point, as discussed in the text. Magnetic field values are in nanoTeslas (nT).

at Hankasalmi in Finland and Pykkvibaer in Iceland, respectively, were operating in the standard mode (e.g. Milan et al., 1997). This mode involves sounding sequentially on all 16 beams (numbered clockwise 0 to 15), with a dwell time on each beam of $7 \mathrm{~s}$, giving a full scan of backscatter with an azimuthal coverage of over $50^{\circ}$ every $2 \mathrm{~min}$. Seventy-five range gates of length $45 \mathrm{~km}$ (numbered 0 to 74 ) are sampled along each beam, with the range of the first gate from the radar itself being $180 \mathrm{~km}$. Transmission of a multi-pulse scheme, comprising seven sub-pulses, allows for the power and spectral width of the returned signal - backscattered from the field-aligned irregularities of decametre order wavelength to which the radars are sensitive - to be estimated by a functional fit to the decorrelation of the auto-correlation function (ACF) within each range cell. The line-of-sight Doppler velocity of the irregularities is determined by a least-squares fit to the phase of the complex value of the ACF.
Figure 1 presents a map depicting the fields-of-view of the CUTLASS Finland and Iceland East radars; beams 7 and 11 of the CUTLASS Finland are indicated explicitly. Also illustrated by thick broken lines are the two beams of the EISCAT VHF radar, from the lowest range gate of power profile observation to the uppermost long pulse gate. The large filled circles represent the locations of the radars themselves; the cross within a circle denotes the geographic pole and the magnetic pole is indicated by the small filled circle.

\section{Observations}

\subsection{Spacecraft observations of the IMF}

Figure 2 presents observations of the interplanetary magnetic field (IMF) from the magnetic field instruments onboard the Wind and ACE spacecraft, lagged to represent the interval 06:45 to 09:45 UT on 23 November 1999 at the subsolar magnetopause. The three panels of this figure illustrate, from the top, the $X, Y$ and $Z$ components of the interplanetary magnetic field, in nT, in geocentric solar magnetic (GSM) coordinates from both the ACE (thick line) and Wind spacecraft (thin line). The time resolution of the magnetic field data from ACE is $16 \mathrm{~s}$ and from Wind, near $90 \mathrm{~s}$. ACE remains situated in the vicinity of the Lagrangian (L1) libration point, some 220 Earth radii $\left(R_{E}\right)$ upstream of the Earth, while during the interval presented the Wind satellite travelled from an $X, Y, Z$ position in GSM coordinates of $(-11.0,-62.7$, $\left.28.6 R_{E}\right)$ to the position $\left(-10.3,-59.9,33.9 R_{E}\right)$; this places Wind well outside the predicted location of the bowshock. As noted previously, observations have been lagged to account for the time taken by the solar wind, with embedded IMF, observed at the spacecraft to impinge upon the subsolar magnetopause, following the work of Khan and Cowley (1999). A time delay of $53 \mathrm{~min}$ has been applied to the magnetometer observations from the ACE satellite; for Wind, however, the corresponding delay is less than one minute. Observations from the two spacecraft become highly consistent once appropriate time delays are applied.

From 06:45 to 07:10 UT, the $Z$ component of the IMF $\left(B_{Z}\right)$ increases rapidly in a southward (negative) direction from near zero to a value of around $-7 \mathrm{nT}$. $B_{Z}$ remains consistently at this level until 08:30 UT, before reducing slowly to $-5 \mathrm{nT}$ over the remainder of the interval. The $Y$ component of the IMF $\left(B_{Y},\right)$ is continuously duskward (positive) throughout the interval of interest, decreasing from its initial value of $8 \mathrm{nT}$ to $3 \mathrm{nT}$ at 07:10 UT before gradually increasing back to its original level. The $X$ component of the $\operatorname{IMF}\left(B_{X}\right)$ is initially directed towards the Earth (negative) but with a value of only around $-1 \mathrm{nT}$. Subsequent to a reversal some 5 min later, $B_{X}$ remains directed away from the Earth (positive), with a typical value of $4 \mathrm{nT}$. Although not shown, the solar wind dynamic pressure derived from the plasma experiments onboard these two spacecraft are also highly consistent during this interval, both revealing a fairly constant pressure of some $2 \mathrm{nPa}$ throughout. 

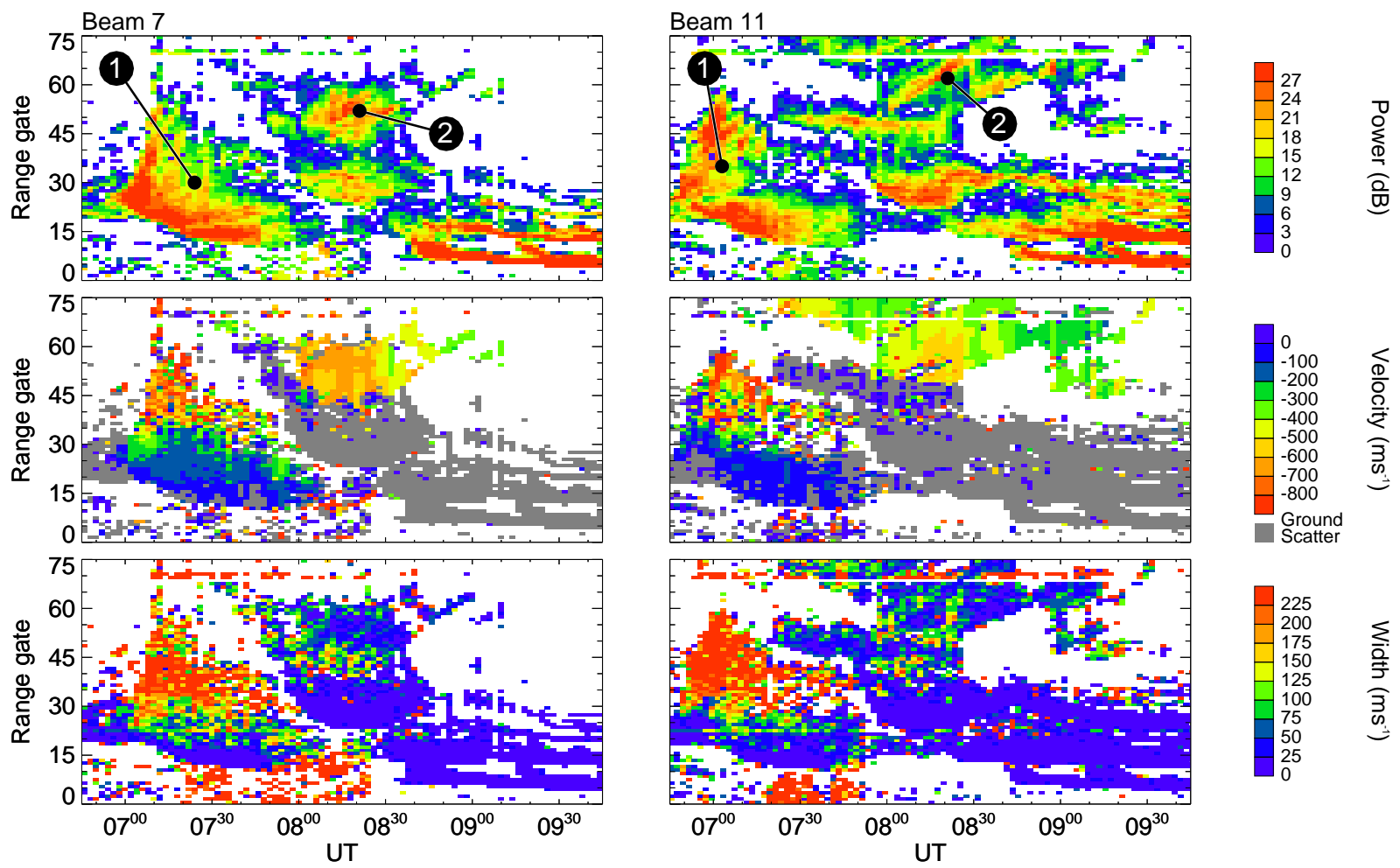

Fig. 3. Observations from beam 7 (left-hand panels) and beam 11 (right-hand panels) of the CUTLASS Finland radar from 06:45 to 09:45 UT on 23 November 1999. For each beam, backscattered power (upper panel), line-of-sight irregularity drift velocity (central panel) and spectral width (lower panel) are presented as a function of range gate; positive drift velocities are those directed towards the radar.

Such a strongly southward orientation of the IMF would be expected to facilitate reconnection, be it impulsive or continuous, near the subsolar magnetopause, driving twincell convection of the high-latitude plasma (see Cowley and Lockwood, 1992, and references therein). The magnetic tension force exerted on the newly open field lines by the large duskward component of the IMF - the well-known Svalgaard-Mansurov effect (Svalgaard, 1973) - would be likely to produce an asymmetry in the convection pattern such that a significant dawnward azimuthal flow component is introduced into the otherwise antisunward flow on the dayside (e.g. Cowley and Lockwood, 1992).

\subsection{CUTLASS HF observations}

Figure 3 presents CUTLASS Finland HF radar observations from beam 7 (left-hand panels) and beam 11 (right-hand panels) during the interval 06:45 to 09:45 UT on 23 November 1999; beams 7 and 11 of the Finland radar are marked explicitly on the map illustrated in Fig. 1. For each beam, backscattered power (upper panel), line-of-sight irregularity drift velocity (central panel) and spectral width (lower panel) are presented as a function of range gate. Positive and negative velocities represent motion of irregularities towards and away from the radar, respectively, although a suitable scale has been adopted to reflect the fact that the vast majority of velocities observed by the Finland radar within this interval are actually away from the radar. The velocities of returns attributed to ground scatter, identified through a combination of narrow spectral width and low Doppler velocity, are indicated in grey. The magnetic latitude coverage of the observations shown is approximately 60 to $90^{\circ}$ and 60 to $84^{\circ}$ for beams 7 and 11, respectively. It should be noted that Altitude Adjusted Corrected Geomagnetic (AACGM) coordinates are used throughout (Baker and Wing, 1989).

There are two main regions of ionospheric scatter, which have been marked 1 and 2 on the upper panels of Fig. 3, which present the backscattered power observations. The region of scatter marked region 1 is evident on both beam 7 and beam 11 from approx. 07:00 to 08:00 UT and between range gates 15 and 60. After an initial rapid expansion along the beams, the region of scatter tends to move towards the radar. Examination of observations from the entire field-ofview of the Finland radar shows the development of a region of HF scatter, initially in the easternmost beams, which then expands westward to cover an extensive portion of the radar field-of-view; this accounts for scatter being observed on beam 11, some 10 minutes earlier than it is seen on the more westward beam 7 . The region of ionospheric scatter then contracts and is replaced by ground scatter. The irregularities within region 1 appear subdivided, roughly according to latitude, into two distinct populations, with the more poleward scatter characterised by high and variable line-ofsight drift velocities and wide spectra, and that at lower lati- 

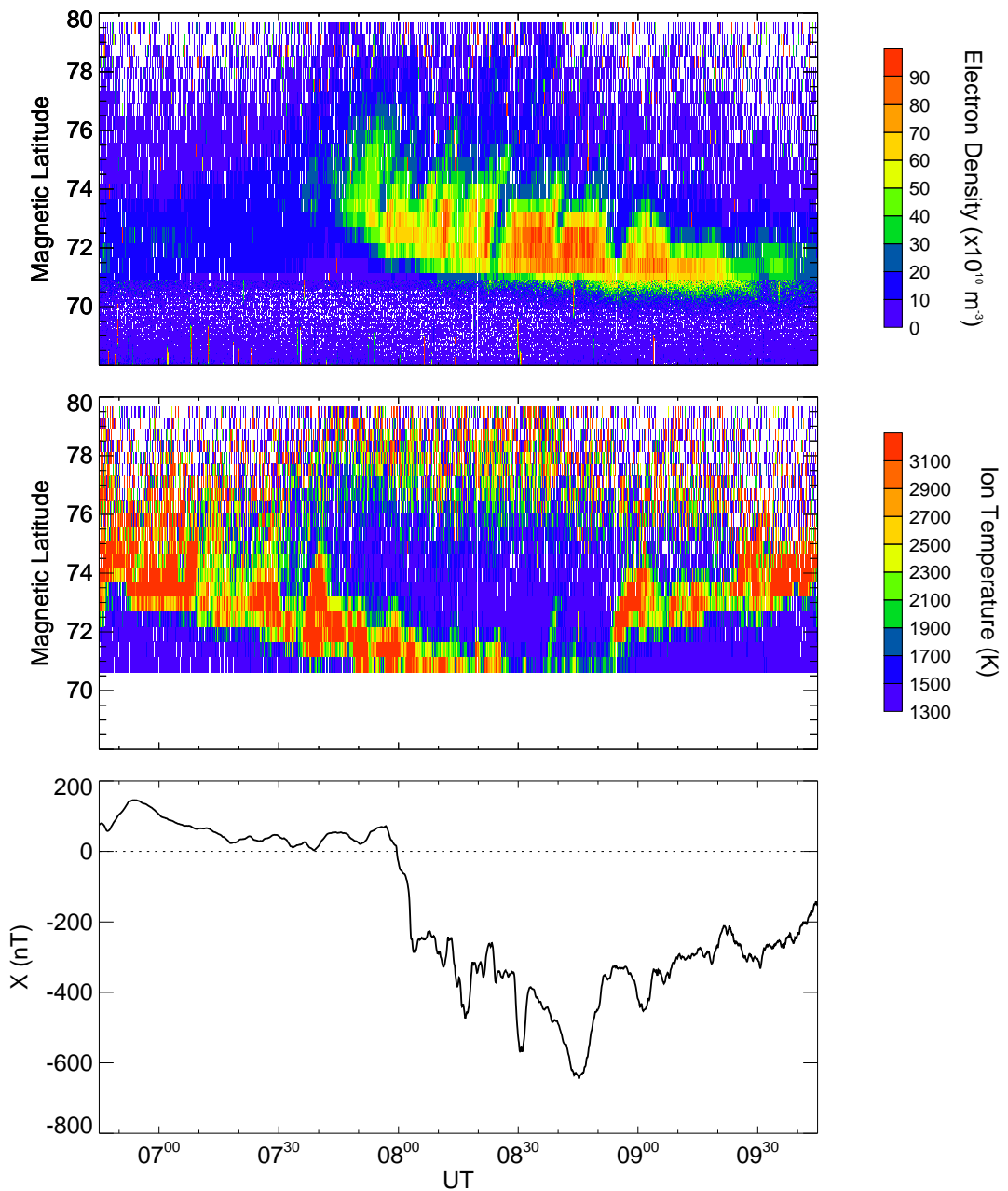

Fig. 4. The top two panels of this figure present electron density (upper panel) and ion temperature measurements (central panel) from beam 1 of the EISCAT VHF radar between 06:45 and 09:45 UT on 23 November 1999 as a function of geomagnetic latitude. The lower panel illustrates the $X$ component in nanoTeslas of the ground magnetic signature from the Fort Smith magnetometer of the CANOPUS chain.

tudes exhibiting lower and more uniform velocities and narrower spectra. Throughout region 1, velocities are directed predominately away from the radar, suggestive of a poleward flow component. There is evidence in both beams that the backscattered power within the poleward (high spectral width) part of region 1 is modulated, with bands of relatively high power, over $30 \mathrm{~dB}$, between which the power is reduced. The poleward part of region 1 also shows evidence of periodic fluctuations in the irregularity drift velocity; however, these features are rather more clear in beam 11. There is evidence that both these patches of enhanced power and velocity propagate along the beam away from the radar. The movement of the transients away from the radar, particularly on beam 7 , which is directed closely towards the magnetic pole, implies a poleward component to their motion.

The second region of ionospheric scatter, marked as region 2 on the backscattered power observations, is again evident in both beams but at further range gates than region 1 . On beam 7, this patch of scatter is observed between 08:00 and 09:00 UT from range gate 45 to 65 ; on beam 11 , the scat- ter is observed over a longer duration, from around 07:20 to 09:20 UT and at most range gates beyond 45. As in the poleward portion of the region 1 scatter, the spectral power is modulated and the power transients propagate away from the radar, implying a poleward motion. However, unlike in region 1 , there is virtually no modulation in the line-ofsight irregularity drift velocity associated with that observed in the spectral power, with antisunward velocities over the whole region typically within the range 300 to $600 \mathrm{~m} \mathrm{~s}^{-1}$. The widths of the coherent scatter spectra within region 2 are generally low, less than $100 \mathrm{~m} \mathrm{~s}^{-1}$, except at its equatorward boundary, where the spectra tend to be somewhat broadened. Some, but not all, of these broader spectra, although classified as of ionospheric origin, contain a large, near zero velocity component, implying that they contain elements of both ground and ionospheric scatter. These echoes, which should not be interpreted literally in a geophysical context, tend to show drift towards the radar, in contrast to the dominant direction of flow, and are interspersed by ground scatter. It is worth stating explicitly that whereas the transients within 
region 2 are associated with narrow spectral widths, this is in marked contrast to the high spectral width scatter in the poleward portion of region 1 where transients are observed.

\subsection{EISCAT VHF observations}

Observations from beam 1 of the EISCAT VHF radar during the interval 06:45 to 09:45 UT on 23 November 1999 are presented in the two uppermost panels of Fig. 4. The top panel of this figure illustrates electron density measurements as a function of AACGM latitude; electron densities below $70.5^{\circ}$ magnetic latitude - equivalent to $280 \mathrm{~km}$ altitude - are derived from the power profile, whereas densities above this latitude are provided by the long pulse scheme. The central panel presents long pulse estimates of ion temperature, again from beam 1 of the VHF radar.

After 07:45 UT, a series of enhancements in F-region electron density are observed by the EISCAT VHF radar, propagating away from the radar, thus poleward. The electron density within these features exhibits up to a tenfold increase over that outside, and the lowest latitude at which successive features are observed tends to migrate equatorwards. The density within the features does, however, tend to reduce markedly as they propagate to higher latitudes, although the quality of the observations can be seen to deteriorate with increasing range from the radar as the signal-to-noise ratio reduces. It must be remembered that an increase in latitude also implies an increase in altitude, so this does not necessarily indicate the limit of their extent, perhaps revealing instead their vertical structure. It is, in fact, demonstrated later that these features do propagate far poleward of where they cease to be observed by the VHF radar. Although observations from beam 1 of the EISCAT VHF radar are presented, as this beam is aligned in azimuth approximately along beam 7 of the CUTLASS Finland radar, similar structure is also evident in the boresight beam, beam 2. Although the same feature can be unambiguously identified in both beams, it appears several minutes earlier in a given range gate on beam 2 , suggesting a westward component to its motion.

The F-region electron density structures appear to emanate from the poleward edge of a moving band of elevated Fregion ion temperature, the latter revealed by the VHF long pulse observations and within which there is a significant degree of structuring. The region of elevated ion temperature progresses equatorward until near 08:30 UT, when only its poleward edge is visible in the VHF observations. Just prior to 09:00 UT, the region of enhanced ion temperatures suddenly reappears in the radar field-of-view, and then proceeds in a poleward direction over the remainder of the interval; this will be discussed in Sect. 4.2. Such enhanced ion temperatures are a consequence of ion frictional heating, resulting from differential flow between the ion and neutral populations in the ionospheric F-region (e.g. Schunk et al., 1975; StMaurice and Schunk, 1979; St-Maurice and Hanson, 1982). At high-latitudes, such relative velocity is most commonly generated by enhancements in the ion flow in response to an imposed electric field; the ion velocity responds on far shorter time scales than the neutral flow, although the prevailing sense of the neutral drift will influence the extent of frictional heating (St-Maurice and Hanson, 1982; Davies et al., 1997; 1999). That the band of high F-region ion temperature corresponds to a region of substantially enhanced velocity is confirmed by invoking a beam swinging technique, combining the line-of-sight ion velocities from corresponding magnetic latitudes along both beams of the VHF radar (not shown). Of course it should be remembered that this technique requires the vector velocity to be constant between the two beams and if this is not the case, spurious flows may be introduced, particularly in circumstances such as these where a large flow shear exists (Lockwood et al., 1988). Nevertheless, the beam swung plasma velocities in this case reveal that the enhanced ion temperatures correspond to large westward flows, which are, in fact, consistent with observations presented in Sect. 4.1.

\subsection{CANOPUS magnetometer observations}

Although reconnection at the magnetopause is a primary influence on the dayside ionosphere, this is not to say that nightside processes have no effect on the dayside. The effect of substorm processes on the present observations are discussed later in Sect. 4.2, specifically with reference to the interpretation of the EISCAT observations. To this end, magnetometer observations from the nightside are presented here. The lower panel of Fig. 4 illustrates the $X$ (north-south) component, in nanoTeslas, of the ground magnetic signature from the Fort Smith magnetometer of the CANOPUS chain. For presentational purposes, the diurnal mean has been subtracted from the absolute values of this component of the magnetic field. The Fort Smith magnetometer station is situated at a magnetic latitude of $67.8^{\circ} \mathrm{N}$ and at $-55.76^{\circ} \mathrm{E}$ magnetic longitude. Near 08:00 UT, which corresponds to a magnetic local time (MLT) of roughly 24:00 MLT, there is a marked negative perturbation in the $X$ component of the ground magnetic field, by some $400 \mathrm{nT}$. This is associated with an enhancement in the westward electrojet current at the onset of the substorm expansion phase, and follows some 90 min during which no activity was observed on the nightside. Following the first expansion phase onset, there is evidence of further substorm activations. Examination of the $X$ and $Z$ (vertical) components from all of the CANOPUS stations reveals that the maximum enhancement in the substorm-associated westward electrojet current occurs at around 22:30 MLT near $70^{\circ}$ magnetic latitude. This corresponds to a location slightly poleward and westward of the Fort Smith magnetometer station, from which data are shown.

\section{Discussion}

\subsection{CUTLASS HF observations}

The region of HF ionospheric scatter marked as region 1 in Fig. 3 (see Sect. 3.2) is considered first. It is suggested 
that the poleward portion of this region of scatter, which as mentioned previously displays high but variable drift velocities and wide spectra, corresponds to the footprint of active magnetic reconnection at the dayside magnetopause, i.e. the ionospheric projection of the cusp. A predisposition for high spectral width HF backscatter within the cusp region has been demonstrated by authors, including Baker et al. (1990; 1995), Pinnock et al. (1995) and André et al. (1999; 2000a; 2000b); in fact, as discussed by Baker et al. (1995), the observation of strong velocity turbulence in the cusp is not unique to HF radars, since it has also been revealed by loworbiting satellites. The reason for this is not yet entirely clear, although André et al. (1999; 2000a) have proposed that wide HF spectra in the cusp may be due to the effect of a time-varying electric field in the 0.1 to $5.0 \mathrm{~Hz}(\mathrm{Pc} 1 / \mathrm{Pc} 2)$ wave band. Alternative mechanisms for the broadening of cusp spectra, dependent on the presence of small-scale spatial structures within the flow pattern, have also been suggested (Schiffler et al., 1997; André et al., 2000b; Huber and Sofko, 2000). Irrespective of the precise physical mechanism responsible for the spectral broadening, the widths of the spectra identified here as resulting from cusp scatter, typically between 200 and $400 \mathrm{~m} \mathrm{~s}^{-1}$, are found to be broadly consistent with those reported by such authors as Baker et al. (1995) and Pinnock et al. (1995), although as detailed by Baker et al. (1995), the concept of spectral width is less meaningful in the cusp region as the spectra tend to be comprised of multiple components. Assuming the region of wide spectra to be representative of the cusp, the region of scatter directly equatorward of this - characterised by narrower spectral width ionospheric scatter with lower and more uniform irregularity drift velocities - will map to closed field lines, with the boundary between the two regimes signifying the open-closed field-line boundary (OCFLB). Previous authors have identified this boundary between high and low spectral width HF scatter on the dayside as providing a reasonable proxy for the OCFLB (e.g. Baker et al., 1995; Milan et al. 1999; Milan and Lester 2001; Moen et al. 2001).

The poleward-propagating enhanced backscatter power features within the poleward part of region 1 and the region 2 scatter (see Sect. 3.2), and the poleward-moving velocity features observed within the former region only, are reminiscent of a number of previous observations of dayside transients by HF radars, which have been suggested to be the signatures of FTEs at the magnetopause. However, it is important here to attempt to clarify the nomenclature that has been used in previous publications for dayside transients observed by HF radars, and to justify the terminology adopted in this paper. As noted in the Introduction, three terms to describe such features are in current usage: flow channel events (FECs) (Pinnock et al., 1993, 1995; Neudegg et al., 1999, 2000), pulsed ionospheric flows (PIFs) (Provan et al., 1998; Provan and Yeoman, 1999; McWilliams et al., 2000) and polewardmoving radar auroral forms (PMRAFs) (Wild et al., 2001). FCEs and PIFs, as their names suggest, describe bursts of enhanced flow in a background of slower-moving plasma. The flow within these features exhibits an enhanced pole- ward component and in the majority of the cases, the features themselves are seen to progress in an antisunward direction. The difference between these two terms is simply that FCEs were identified by their spatial characteristics, whereas PIFs were identified from their temporal evolution. It is unfortunate that in some publications, the term PIF has been used to describe a discrete poleward-propagating region of high velocity backscatter, such that adjacent PIFs are separated by a region in which there is an absence of HF scatter denoting a returned power lower than the noise level. In the case of such HF radar observations, it is impossible to determine whether the flow is itself pulsed or the pulsing is merely in the observations. In fact, this ambiguity was part of the reason for the introduction of the term PMRAF, which simply describes a poleward-moving transient observed in backscattered power.

The present observations are unlike many of those previously published in which each transient tends to comprise an isolated region of scatter. In this case, the backscatter power between each transient is reduced, but not to such an extent that the scatter is completely lost. The cusp scatter of region 1 shows poleward-moving structures in both the returned power and the line-of-sight irregularity drift velocity; the former is consistent with what has been termed PMRAFs and the latter, PIFs. In the region 2 scatter, there is no evidence of pulsing in the flow such that only PMRAFs are observed within this region. Although the individual transients are not very well defined, due to relatively low temporal resolution of observations along a single beam (120 s), their recurrence rate appears to be of the order of $10 \mathrm{~min}$, a figure that is similar in all beams over which the region 2 scatter is observed. This value concurs well with previous studies of HF transients (Provan et al., 1998; McWilliams et al., 2000) and, indeed, the repetition rate of FTEs observed at the magnetopause (Rijnbeek et al., 1984; Lockwood and Wild, 1993; Kuo et al., 1995). Their occurrence, under conditions of a southward oriented IMF, is also consistent with previously documented studies of HF transients (e.g. McWilliams et al., 2000) and FTEs (e.g. Rijnbeek et al., 1984; Kuo et al., 1995; Kawano and Russell, 1997).

Figure 5a presents spatial maps of line-of-sight irregularity drift velocity (upper panel) and spectral width (lower panel) from the CUTLASS Finland (left-hand panels) and Iceland East radars (right-hand panels) for the two-minute scan starting at 07:34 UT; Fig. 5b presents maps, in an identical format, for the scan starting at 08:10 UT. Maps are plotted in magnetic latitude and MLT coordinates, with radial dotted lines marking MLT meridians (12:00 MLT vertically upwards) and concentric dotted circles representing magnetic latitudes of 60,70 and $80^{\circ}$. As in Fig. 3, positive (blue) drift velocities are those directed towards the radar, although it must be noted that in contrast to Fig. 3, the velocity scale in Fig. 5 is symmetric around zero. Moreover, ground scatter is marked in grey on both velocity and width panels. Overlaid on each panel are contours of the electrostatic potential, with solid and dashed lines indicating contours of negative and positive potentials, respectively. Values of the potential (in $\mathrm{kV}$ ) are marked on the top, left-hand panel of each fig- 


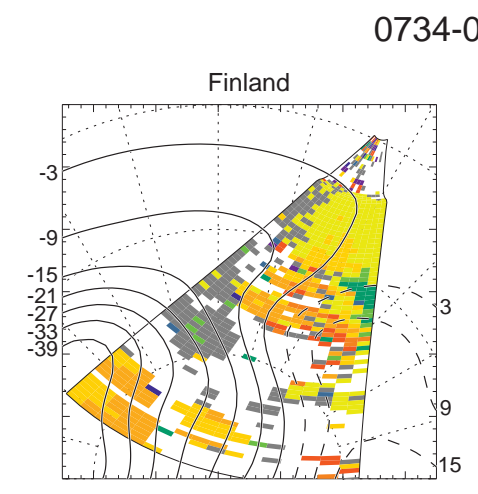

0734-0736 UT
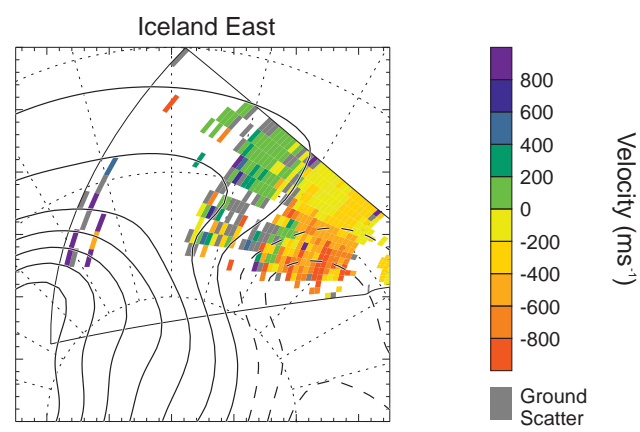

(a)
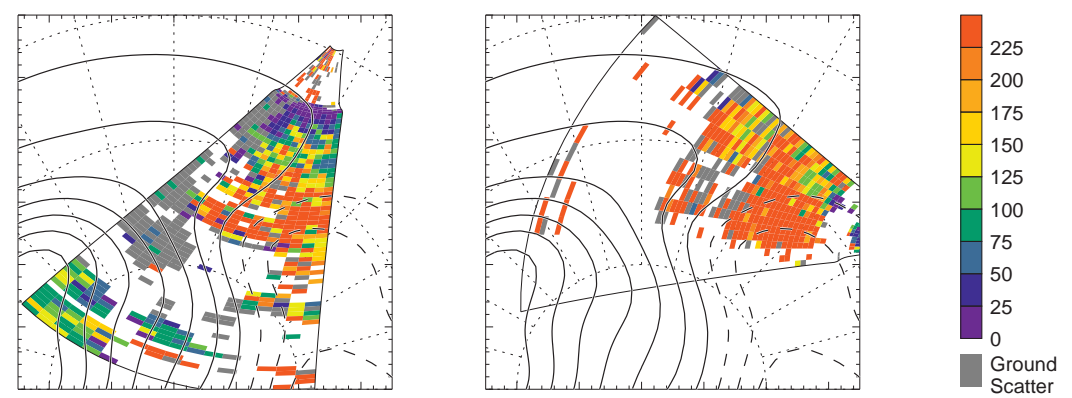

0810-0812 UT
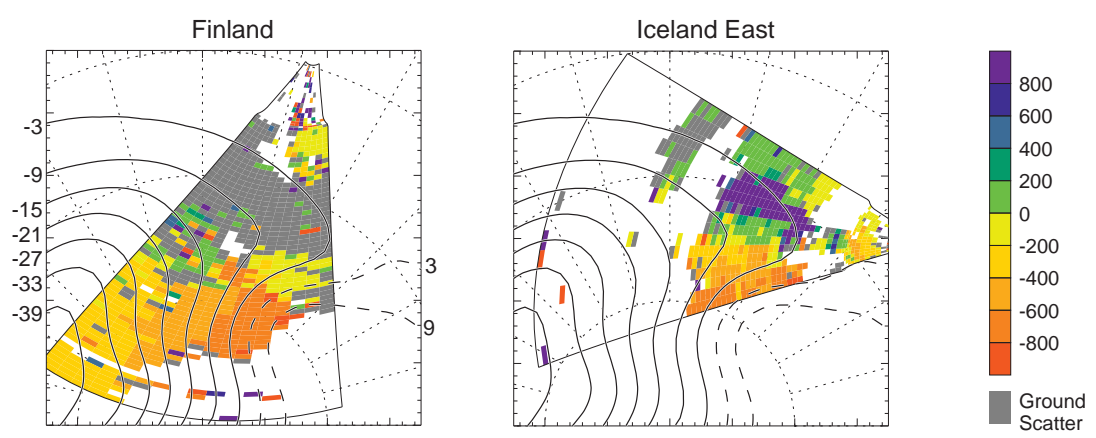

$$
\text { 亦 }
$$

商

(b)
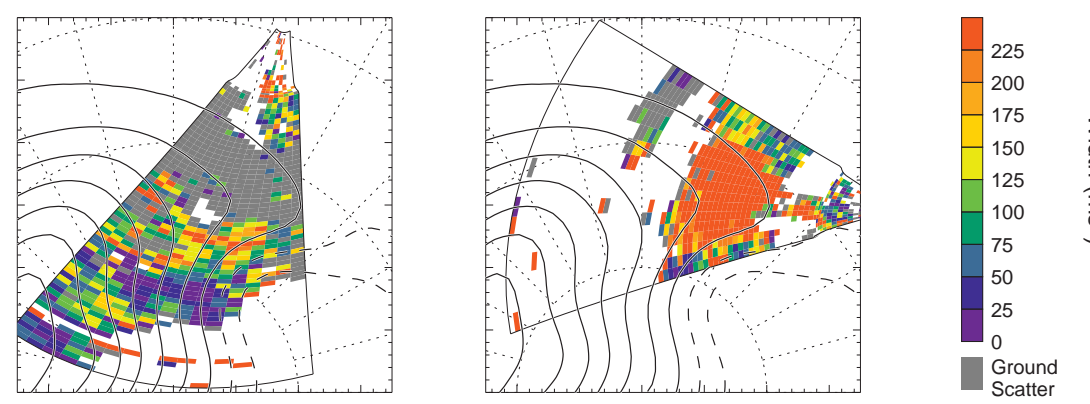

产

Fig. 5. (a) The left- and right-hand panels of this figure illustrate spatial maps of line-of-sight irregularity drift velocity (upper panel) and spectral width (lower panel) from the CUTLASS Finland and Iceland East radars, respectively, for the scan starting at 07:34 UT. Maps are plotted in magnetic latitude and magnetic local time (MLT) coordinates; radial dotted lines indicate MLT meridians, with 12 MLT vertically upwards, while concentric dotted circles represent magnetic latitudes of 60,70 and $80^{\circ}$. Positive drift velocities are those directed towards the radar. Overlaid on each panel are contours of the electrostatic potential, derived using the technique developed by Ruohoniemi and Baker (1998) as discussed in the text, with solid and dashed lines indicating negative and positive potentials, respectively. (b) As for Fig. (a), for the scan starting at 08:10 UT. 
ure. The potential pattern is derived from the line-of-sight velocities of all available Northern Hemisphere SuperDARN radars, using the spherical harmonic potential fitting technique developed by Ruohoniemi and Baker (1998). In this case, the fit has been expanded to an order 8, constrained at its equatorward edge to a magnetic latitude of $60^{\circ}$. Calculation of the potential pattern is stabilised by the statistical model of Ruohoniemi and Greenwald (1996), for the prevailing IMF conditions.

Observations from the entire field-of-view of the Finland radar for the scan starting at 07:34 UT (Fig. 5a) reveal the full spatial extent of the region 1 scatter at that time, covering from 65 to $75^{\circ}$ in magnetic latitude and some two hours of MLT. The high spectral widths measured by the Finland radar in the poleward portion of region 1 - characteristic of the cusp - are also present roughly in the same location by the Iceland East observations. Moreover, the Iceland East observations from 08:10 UT, presented in Fig. 5b, confirm that this region of wide spectra still exists even when it has been obscured by ground scatter in the Finland field-ofview. Both of the scans show twin cell convection, typical of that which would be expected under the conditions of a strongly southward IMF present during this interval in response to reconnection at the subsolar magnetopause (Cowley and Lockwood, 1992). The large, positive $B_{Y}$ produces, via the Svalgaard-Mansurov effect, an asymmetry in the convection pattern such that a significant westward flow component is introduced into the cusp region (i.e. region 1); this evolves at more poleward latitudes into a more antisunward directed flow. Again, this is consistent with the theoretical flow response described by such authors as Cowley and Lockwood (1992). The PIFs observed in the region 1 scatter can be explained in terms of the large bursts of azimuthal flow produced in the cusp by FTEs under conditions of a large $Y$ component of IMF.

The evolution from an aziumthal, $B_{Y}$ dominated, flow to a more antisunward directed flow regime at higher latitudes strongly supports the idea that the PMRAFs have migrated poleward from lower latitudes, i.e. from region 1, through that region in which propagation conditions mean that the PMRAFs themselves cannot be observed. It is actually the source-mechanism for the generation of field-aligned irregularities that propagates, rather than the irregularities themselves, as the latter only has a lifetime of the order of seconds (e.g. Tsunoda, 1988). It can, therefore, be inferred that the PMRAFs originate in the region of high spectral width cusp scatter, where they are accompanied by PIFs. These observations show clearly a reduction in the spectral width, as the PMRAFs move with respect to the cusp and, moreover, in the difference in the velocity fields of the two regions. Again, it should be remembered that some of the spectra on the equatorward edge of the region of PMRAFs contain elements of ground scatter. It is unfortunate that the PMRAFs and their source region are separated, thus masking the evolution of scatter between these two regimes.

Although it is thought that the PMRAFs form in the cusp region in response to transient reconnection, it is not necessarily obvious whether their poleward propagation traces the motion of the footprint of transient reconnection itself or whether PMRAFs instead reveal fossil signatures of FTEs, i.e. signatures which, although generated by FTE activity, persist beyond the interval of active reconnection. Observations presented by McWilliams et al. (2001) suggested that only for the first part of its lifetime in the radar field-of-view, did an HF transient map the footprint of an active reconnection region, moving mainly longitudinally under the magnetic tension force induced by the IMF $B_{Y}$ component and with a phase velocity roughly twice the convection speed. After this, the transient slowed to the convection velocity, moving antisunward with the reconnected field lines. It should be stated that the study of McWilliams et al. (2001) was exceptional in that twodimensional vector observations of the convection pattern were available throughout the ionospheric footprint of an FTE. The authors noticed a reduction in the spectral width of the feature as it propagated, as is also evident in the present observations. It is deemed likely, although this was not stated explicitly by McWilliams et al. (2001), that the reduction in spectral width reflects the PMRAF leaving the region of active reconnection. This is very much confirmed by the fact that in the region 1 scatter they are accompanied by PIFs and this is not so in the region 2 scatter.

\subsection{EISCAT VHF observations}

The EISCAT VHF observations presented in Sect. 3 reveal, in summary, a series of F-region electron density enhancements propagating poleward from a region characterised by high ion temperature, the latter resulting from ion frictional heating in the presence of large, mainly azimuthal ion flows. Modelling work has suggested that a band of high ion temperatures, enhanced through frictional heating, will form on the low-latitude side of a contracting OCFLB and on the high-latitude side of an expanding boundary (Lockwood and Fuller-Rowell, 1987a, b); this is supported by observations by Lockwood et al. (1988). This supports the idea that the equatorward edge of the region of high ion temperature observed here represents the OCFLB. The large-scale equatorward motion of this region of enhanced flow before 08:30 UT results from the addition of flux to the polar cap on the dayside under the prevailing southward IMF conditions. The reversal in the general sense of motion of this feature after 08:30 UT can be explained by the observation of intense substorm activity around this time on the nightside, as diagnosed principally in magnetometer data from the CANOPUS chain (see Fig. 3), leading to a poleward motion of the polar cap boundary, despite the fact that open magnetic flux is still being added to the polar cap on the dayside under continuing conditions of southward IMF.

There is little doubt that formation of the polewardmoving plasma density enhancements is related in some way to this band of enhanced ion temperature; indeed, the ion temperature within this region is pulsed with a period comparable to that observed at higher latitudes in the electron 

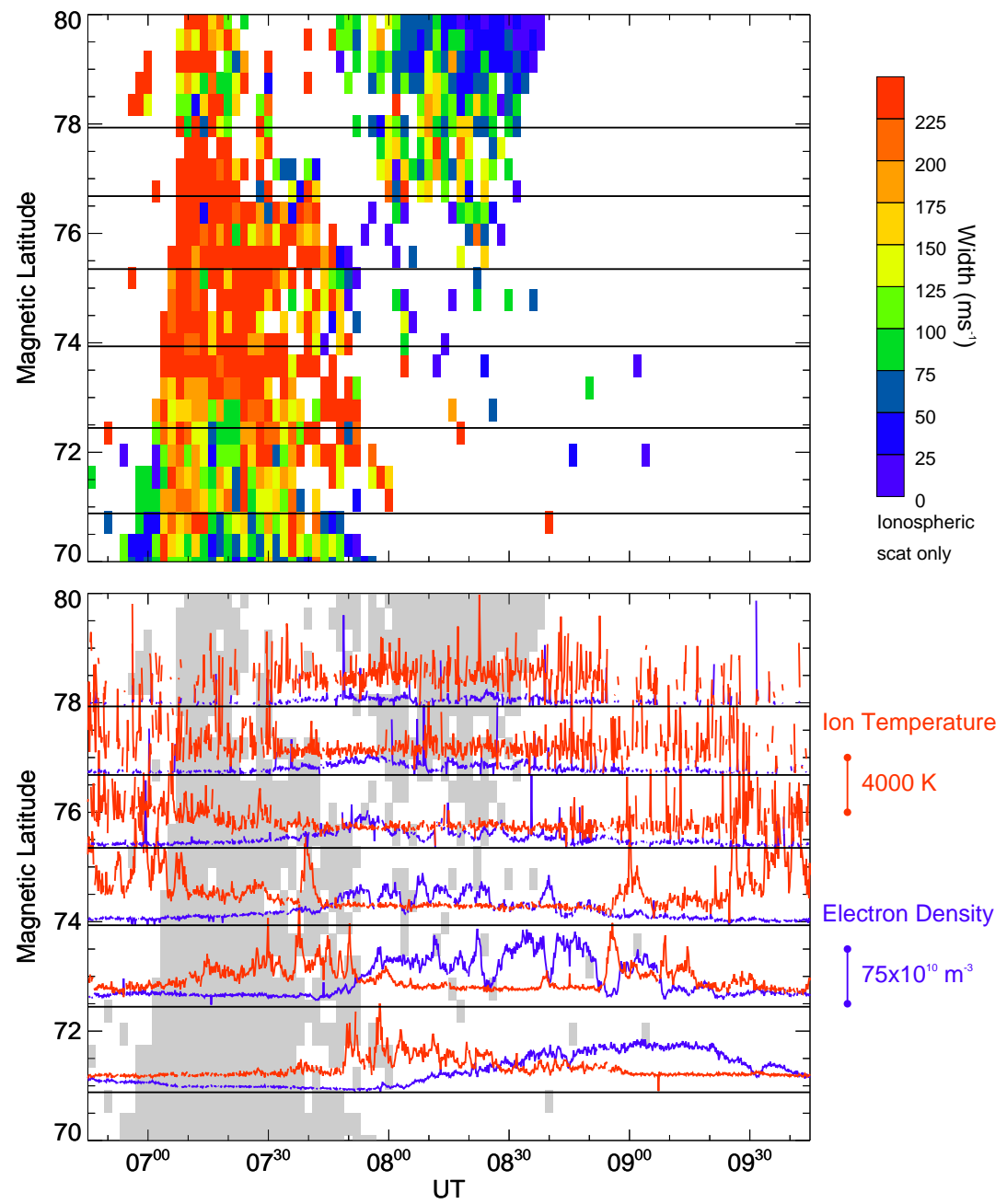

Fig. 6. The upper panel of this figure illustrates spectral width measurements from beam 7 of the CUTLASS Finland radar from $06: 45$ to 09:45 UT on 23 November 1999 as a function of magnetic latitude. The lower panel illustrates, over the same time interval and latitude range, time series of F-region electron density (blue) and ion temperature (red) from selected range gates along beam 1 of the VHF radar. The horizontal back lines indicate the latitudes corresponding to these gates and act as their baseline levels, and the vertical lines, appropriately coloured, indicate the scales. The light grey shading shows, for guidance, the extent of the ionospheric scatter presented in the top panel.

density. It can thus be inferred that the formation region of these density features is near the OCFLB from where they propagate into polar cap. There have been several other reported incoherent scatter radar sightings of F-region plasma density enhancements convecting through the cusp region and into the polar cap. Foster and Doupnik (1984) observed poleward-moving density structures with the Chatanika radar in Alaska, while Lockwood and Carlson (1992) detected their presence with the EISCAT UHF radar system. Recent authors, for example Lockwood et al. (2000, 2001), have documented EISCAT Svalbard radar (ESR) observations of such features. Such plasma density structures fall under the remit of what has been termed "polar cap patches" (e.g. Weber et al., 1984; Sojka et al., 1993; Rodger et al., 1994), although this term does encompass features with a large range of scale sizes. Although polar patches are a ubiquitous feature of the polar F-region under conditions of southward IMF, the exact physical mechanism by which they are created is the subject of continuing debate (see Lockwood et al., 2001). What is generally accepted though is that once formed, they can migrate for great distances across the polar cap, preserved by the long lifetime of plasma in the F-region.

The series of discrete poleward-moving density patches observed by Lockwood and Carlson (1992) was interpreted by the authors as resulting from changes in the pattern of flow, associated with transient magnetopause reconnection, modulating the entry into the polar cap of pre-existing solar produced plasma from sub-auroral latitudes. Modelling work documented by Sojka et al. (1993) supports this idea that solar-produced plasma from lower latitudes can become entrained in the high-latitude convection pattern; however, in that case, the authors attributed the fragmentation of the plasma into patches to temporal variations in the $Y$ component of the IMF. Rodger et al. (1994) proposed that the struc- 


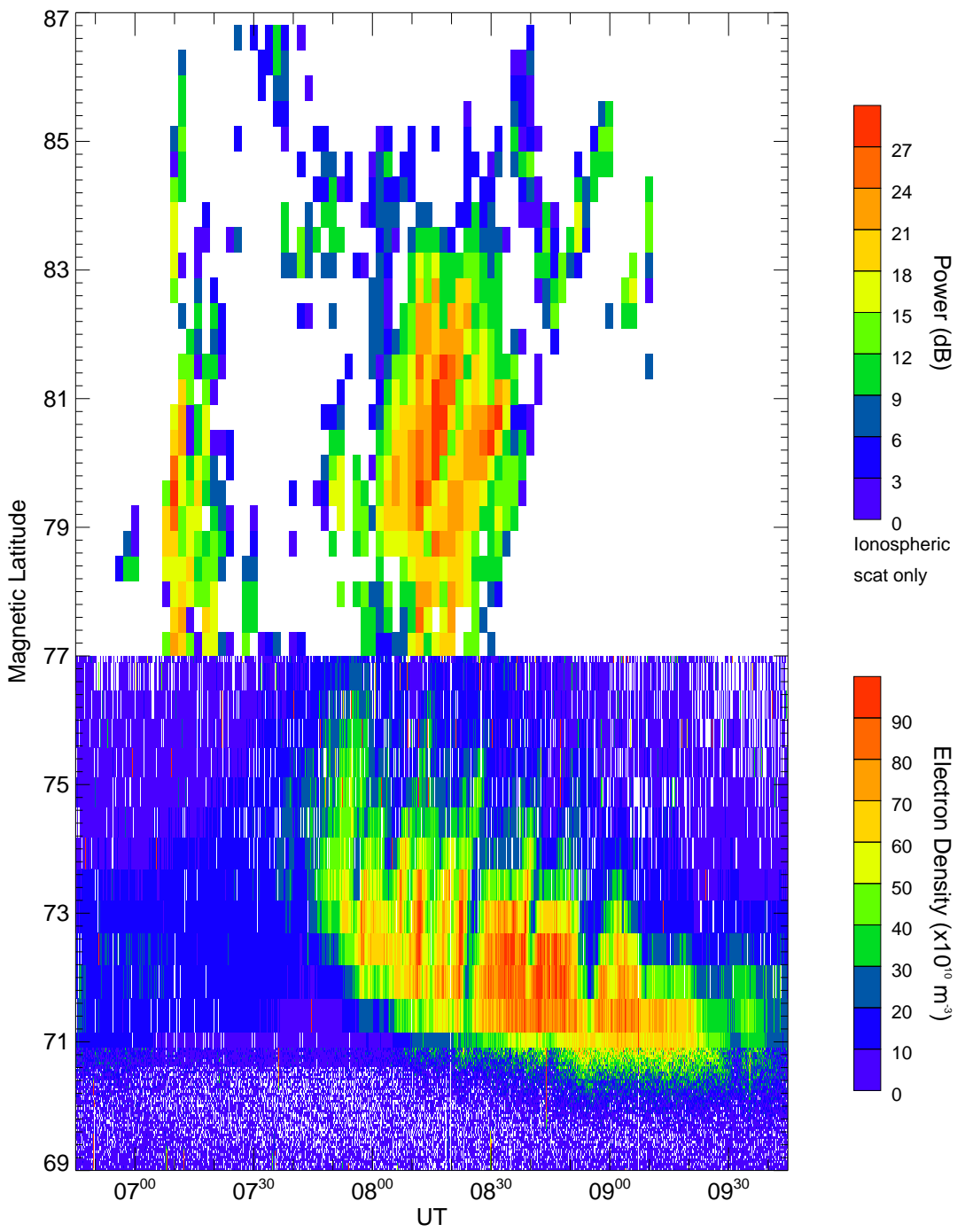

Fig. 7. Composite plot of backscattered power from beam 7 of the CUTLASS Finland radar and electron density from beam 1 of the EISCAT VHF radar, as a function of magnetic latitude between 0645 and 09:45 UT on 23 November 1999. Observations below $77^{\circ}$ are from the VHF radar and those above, from the Finland radar.

turing of ionisation in polar patches was a consequence of enhanced recombination of plasma in regions of high plasma flow. Although Rodger et al. (1994) deemed that it was changes in IMF $B_{Y}$ that were responsible for the creation of such plasma structuring, such a senario would also be expected in any situation where large flows are generated, and this will include intervals of transient reconnection, especially under the influence of a large $B_{Y}$. It has also been suggested that the enhanced densities within polar patches can be produced through collisional ionisation, in response to magnetosheath particle precipitation (e.g. Weber et al., 1984; Davis and Lockwood, 1996). In the work of Davis and Lockwood (1996), the authors simulated a series of such features in ESR data by imposing episodic precipitation on a model ionosphere, such as would be expected to result from a series of FTEs. Lockwood et al. (2001) have observed recently polar patches associated with enhancements in the fluxes of ions and electrons observed by Cluster in the mantle. During that part of the interval over which patches are observed, the $Y$ component of the IMF remains approximately constant (see Fig. 2). This is very much supportive of the discrete nature of the F-region density features being related instead to a series of reconnection pulses. Lockwood et al. (2000) have concluded that all of the above mechanisms contributed in some degree to the formation of the patches presented by the authors. This is likely to be the case in the present observations.

Whatever the specific formation mechanism of these plasma patches, there is little doubt that they originate in the cusp, from where they propagate poleward into the polar cap in the prevailing poleward convection as the fossil remains of transient reconnection. It is this fact, and not the origin of the plasma, that is of paramount importance when the VHF and HF observations are compared in the next section. 
4.3 Comparison of the CUTLASS and EISCAT observations

In this section, the CUTLASS Finland HF coherent scatter observations are compared to the incoherent scatter observations from the EISCAT VHF radar. The upper panel of Fig. 6 illustrates spectral width measurements from beam 7 of the CUTLASS Finland radar from 06:45 to 09:00 UT on 23 November 1999, as a function of magnetic latitude from 70 to $80^{\circ}$; any $\mathrm{HF}$ returns identified as ground scatter, by virtue of their velocity and spectral width, have been excluded. The lower panel of this figure illustrates over the same time interval and latitude range time series of long pulse estimates of F-region electron density (blue) and ion temperature (red) from selected range gates along beam 1 of the VHF radar. The horizontal black lines indicate the latitudes corresponding to these gates and act as their baseline levels, and the appropriately coloured vertical lines at the side indicate the scales. The light grey shading shows, for guidance, the extent of the ionospheric scatter presented in the top panel.

The upper panel of this figure shows clearly the marked difference between the spectral width of the irregularities within the PMRAFs themselves (of which only the equatorward portion is shown) and the region of broad spectra identified as the cusp, from where they were demonstrated to originate (see Sect. 4.1). The lower panel reveals that the high spectral width scatter observed by the HF radar is colocated with the region of high and variable ion temperatures and thus flows, both of which are consistent with this being the footprint of active reconnection. There are regions of intense frictional heating where there is an absence of scatter, but due to the nature of HF propagation a lack of scatter in a given range gate does not necessarily imply anything about the characteristics of the irregularities therein. It is heartening to find that the region of lower spectral width and, therefore, less turbulent scatter, which lies equatorward of this cusp scatter and has been proposed to correspond to closed field lines, does indeed correspond to a region of more quiescent plasma conditions.

Like Fig. 3, Fig. 6 shows the distinct change in the plasma directly poleward of the cusp region. This region of high and variable flows is replaced by a regime of more quiescent conditions but with the presence of the plasma patches. This latter region is unfortunately masked in the HF data by an absence of ionospheric scatter. In order to reveal the relationship between the PMRAFS and prevailing conditions in the ionospheric plasma, the data are presented in the format of Fig. 7. Figure 7 presents a composite plot of backscattered power from beam 7 of the CUTLASS Finland radar and electron density from beam 1 of the EISCAT VHF radar between 06:45 and 09:00 UT on 23 November 1999. The data are plotted from 69 to $87^{\circ}$ magnetic latitude, with those observations below $77^{\circ}$ being electron density from the incoherent scatter radar and those above, backscattered power from its coherent counterpart. As in the previous figure, only $\mathrm{HF}$ observations identified as originating from ionospheric scatter are included. As in Fig. 4, electron densities below $70.5^{\circ}$ magnetic latitude are derived from the power profile, whereas densities above this latitude are provided by the long pulse scheme.

There is only limited latitudinal overlap between the transients observed in HF and VHF data, with the transients observed by the HF radar lying poleward of those observed by EISCAT. However, as noted previously, it can be inferred that the PMRAFs have migrated poleward, and have, therefore, passed through the region in which the F-region electron density patches are observed by the VHF radar. The reduction in the electron density within the patches as they move to the further ranges is assumed to be an altitude effect rather than indicating the limit of their poleward extent. It is known that the formation of irregularities in the HF backscatter features via the gradient drift requires an electron density gradient. Therefore, it is highly probable that the regions of antisunward-propagating enhanced F-region electron density observed by the EISCAT VHF radar, continue to propagate poleward for many hundreds of kilometres beyond that region which can be probed by the VHF radar and it is the gradients on the trailing edge of these features which create the field-aligned irregularities within the PMRAFs observed by the Finland radar. By viewing the combined EISCAT VHF and CUTLASS Finland HF radar observations in this way, the motion of these patches of enhanced F-region plasma density, which originate in the vicinity of the cusp, can be tracked over a distance of some $1700 \mathrm{~km}$, equivalent to $15^{\circ}$ of latitude. This provides, of course, only a lower limit to their potential lifetime and it is not inconceivable that, given the long recombination times in the polar F-region, the ambient antisunward flow can transport these features well into the nightside.

\section{Summary}

EISCAT VHF observations have revealed a series of Fregion electron density enhancements, travelling antisunward through the polar cap, under conditions of a strongly southward IMF. These observations were associated with PMRAFs detected by the CUTLASS Finland HF radar. Such PMRAFs, commonly observed by HF radars near noon, are generally interpreted as the radar signature of flux transfer events. However, the precise physical mechanism for the generation of field-aligned irregularities within such features, and hence, their exact relationship to the particle precipitation and large electric fields which arise in the cusp in response to magnetopause reconnection, is not well determined. This work provides compelling evidence that these poleward-propagating HF backscatter features are most likely formed in electron density gradients produced by structuring of the ionosphere within the cusp region. The PMRAFs become narrow in spectral width as they evolve away from more classical cusp scatter from which they emanate; in the cusp scatter they are accompanied by PIFs. It is concluded that over much of their lifetime, when they are in 
fact in the polar cap, the PMRAFs trace fossil signatures of transient reconnection rather than revealing the footprint of active reconnection itself.

Acknowledgements. The authors are indebted to the director and staff of EISCAT for operating the facility and supplying the data and to the EISCAT group at the Rutherford Appleton Laboratory for maintenance of the analysis software and assistance therewith. EISCAT is an international facility funded collaboratively by the research councils of Finland (SA), France (CNRS), the Federal Republic of Germany (MPG), Japan (NIPR), Norway (NAVF), Sweden (NFR) and the United Kingdom (PPARC). CUTLASS is funded jointly by PPARC (Grant number PPA/R/R/1997/00256), the Swedish Institute for Space Physics, Uppsala, and the Finnish Meteorological Institute, Helsinki. The authors acknowledge the principal investigators R. Lepping and N. Ness for enabling use of the Wind and ACE MFI key parameter data, respectively. Thanks are also due to the Canadian Space Agency for providing the CANOPUS magnetometer data. J. A. Davies and S. E. Milan are supported on PPARC grant number PPA/G/O/1999/00181. I. J. Rae is supported by the Natural Sciences and Engineering Council of Canada (NSERC). K. A. McWilliams is funded by the Association of Commonwealth Universities of the British Council.

The Editor in Chief thanks F. Sedgemore-Schulthess for his help in evaluating this paper.

\section{References}

André, R., Pinnock, M., and Rodger, A. S.: On the autocorrelation function observed in the ionospheric cusp, Geophys. Res. Lett., 26, 3353-3356, 1999.

André, R., Pinnock, M., and Rodger, A. S.: Identification of the low-altitude cusp by Super Dual Auroral Radar Network radars: a physical explanation for the empirically derived signature, J. Geophys. Res., 105, 27 081-27 093, 2000a.

André, R., Pinnock, M., Villain, J.-P., and Hanuise, C.: On the factor conditioning the Doppler spectral width determined from SuperDARN HF radars, Int. J. Geomag. Aeronomy, 2, 77-86, 2000b.

Baker, K. B. and Wing, S.: A new magnetic coordinate system for conjugate studies at high latitudes, J. Geophys. Res., 94, 91399143, 1989.

Baker, K. B., Greenwald, R. A., Ruohoniemi, J. M., Dudeney, J. R., Pinnock, M., Newell, P. T., Greenspan, M. E., and Meng, C.I.: Simultaneous HF-radar and DMSP observations of the cusp, Geophys. Res. Lett., 17, 1869-1872, 1990.

Baker, K. B., Dudeney, J. R., Greenwald, R. A., Pinnock, M., Newell, P. T., Rodger, A. S., Mattin, N., and Meng, C.-I.: HF radar signatures of the cusp and low-latitude boundary layer, J. Geophys. Res., 100, 7671-7695, 1995.

Cowley, S. W. H. and Lockwood, M.: Excitation and decay of solar wind-driven flows in the magnetosphere-ionosphere system, Ann. Geophysicae, 10, 103-115, 1992.

Davies, J. A., Lester, M., and McCrea, I. W.: A statistical study of ion frictional heating observed by EISCAT, Ann. Geophysicae, 15, 1399-1411, 1997.

Davies, J. A., Lester, M., and McCrea, I. W.: Solar and seasonal dependence of ion frictional heating, Ann. Geophysicae, 17, 682691, 1999.

Davies, J. A., Yeoman, T. K., Rae, I. J., Milan, S. E., Lester, M., McWilliams, K. A., and Lockwood, M.: A comparison of F- region ion velocity observations from the EISCAT Svalbard and VHF radars with irregularity drift velocity measurements from the CUTLASS Finland HF radar, Ann. Geophysicae, 18, 589594, 2000.

Davis, C. J. and Lockwood, M.: Predicted signatures of pulse reconnection in ESR data, Ann. Geophysicae, 14, 1246-1256, 1996.

Fasel, G. J.: Dayside poleward moving auroral forms: a statistical study, J. Geophys. Res., 100, 11 891-11 905, 1995.

Foster, J. C. and Doupnik, J. R.: Plasma convection in the vicinity of the cleft, J. Geophys. Res., 89, 9107-9113, 1984.

Goertz, C. K., Nielsen, E., Korth, A., Glaßmeier, K.-H., Haldoupis, C., Hoeg, P., and Hayward, D.: Observations of a possible signature of flux transfer events, J. Geophys. Res., 90, 4069-4078, 1985.

Haerendel, G., Paschmann, G., Sckopke, N., Rosenbauer, H., and Hedgecock, P. C.: The frontside boundary layer of the magnetopause and the problem of reconnection, J. Geophys. Res., 83, 3195-3216, 1978.

Huber, M. and Sofko, G. J.: Small-scale vortices in the high-latitude F-region, J. Geophys. Res., 105, 20 885-20 897, 2000.

Kawano, H. and Russell, C. T.: Survey of flux transfer events observed with the ISEE 1 spacecraft: dependence on the interplanetary magnetic field, J. Geophys. Rev, 102, 11 307-11313, 1997.

Khan, H. and Cowley, S. W. H.: Observations of the response time of high-latitude ionospheric convection to variations in the interplanetary magnetic field using EISCAT and IMP-8 data, Ann. Geophysicae, 17, 1306-1335, 1999.

Kuo, H., Russell, C. T., and Lee, G.: Statistical studies of flux transfer events, J. Geophys. Res., 100, 3513-3519, 1995.

Lockwood, M. and Fuller-Rowell, T. J.: The modelled occurrence of non-thermal plasma in the ionospheric F-region and the possible consequences for ion outflows into the magnetosphere, Geophys. Res. Lett., 14, 371-374, 1987a.

Lockwood, M. and Fuller-Rowell, T. J.: Correction to "The modelled occurrence of non-thermal plasma in the ionospheric Fregion and the possible consequences for ion outflows into the magnetosphere", Geophys. Res. Lett., 14, 581-581, 1987b.

Lockwood, M., Cowley, S. W. H., Todd, H., Willis, D. M., and Clauer, C. R.: Ion flows and heating at a contracting polar-cap boundary, Planet. Space Sci., 11, 1229-1253, 1988.

Lockwood, M. and Carlson, H. C.: Production of polar cap electron density patches by transient magnetopause reconnection, Geophys. Res. Lett., 19, 1731-1734, 1992.

Lockwood, M. and Smith, M. F.: The variation of reconnection rate at the dayside magnetopause and cusp ion precipitation, J. Geophys. Res., 97, 14 841-14 847, 1992.

Lockwood, M. and Wild, M. N.: On the quasi-periodic nature of magnetopause flux transfer events, J. Geophys. Res., 98, 59355940, 1993.

Lockwood, M. and Smith, M. F.: Low- and mid-altitude cusp particle signatures for general magnetopause reconnection rate variations, 1. Theory, J. Geophys. Res., 99, 8531-8553, 1994.

Lockwood, M., McCrea, I. W., Milan, S. E., Moen, J., Cerisier, J.-C., and Thorolfsson, A.: Plasma structure within polewardmoving cusp/cleft auroral transients: EISCAT Svalbard radar observations and an explanation in terms of large local time extent of events, Ann. Geophysicae, 18, 1027-1042, 2000.

Lockwood, M., Opgenoorth, H., van Eyken, A. P., et al.: Coordinated Cluster, ground-based instrumentation and low-altitude satellite observations of transient poleward-moving events in the ionosphere and in the tail lobe, Ann. Geophysicae, 19, 1589$1612,2001$. 
McWilliams, K. A., Yeoman, T. K., and Provan, G.: A statistical survey of dayside pulsed ionospheric flows as seen by the CUTLASS Finland HF radar, Ann. Geophysicae, 18, 445-453, 2000.

McWilliams, K. A., Yeoman, T. K., and Cowley, S. W. H.: Twodimensional electric field measurements in the ionospheric footprint of a flux transfer event, Ann. Geophysicae, 18, 1584-1598, 2001.

Milan, S. E. and Lester, M.: Interhemispheric differences in the HF radar signature of the cusp region: a review through the study of a case example, Adv. Polar Upper Atmos. Res., 15, 159-177, 2001.

Milan, S. E., Yeoman, T. K., Lester, M., Thomas, E. C., and Jones, T. B.: Initial backscatter occurrence statistics from the CUTLASS HF radars, Ann. Geophysicae, 15, 703-718, 1997.

Milan, S. E., Lester, M., Cowley, S. W. H., Moen, J., Sandholt, P. E., and Owen, C.: Meridian-scanning photometer, coherent HF radar and magnetometer observations of the cusp: a case study, Ann. Geophysicae, 17, 159-172, 1999.

Milan, S. E., Lester, M., Cowley, S. W. H., and Brittnacher, M.: Convection and auroral response to a southward turning of the IMF: Polar UVI, CUTLASS and IMAGE signatures of transient magnetic flux transfer at the magnetopause, J. Geophys. Res., 105, 15 741-15 755, 2000.

Moen, J., Carlson, H. C., Milan, S. E., Shumilov, N., Lybekk, B., Sandholt, P. E., and Lester, M.: On the collocation between dayside activity and coherent HF backscatter, Ann. Geophysicae, 18, 1531-1549, 2001.

Neudegg D. A., Yeoman, T. K. Cowley, S. W. H., Provan, G., Haerendel, G., Baumjohann, W., Auster, U., Fornacon, K.-H., Georgescu, E., and Owen, C. J.: A flux transfer event observed at the magnetopause by the Equator-S spacecraft and in the ionosphere by the CUTLASS HF radar, Ann. Geophysicae, 17, 707711, 1999.

Neudegg D. A., Cowley, S. W. H., Milan, S. E., Yeoman, T. K., Lester, M., Provan, G., Haerendel, G., Baumjohann, W., Nikutowski, B., Büchner, J., Auster, U., Fornacon, K. H., and Georgescu, E.: A survey of magnetopause FTEs and associated flow bursts in the ionopshere, Ann. Geophysicae, 18, 416-435, 2000.

Pinnock, M., Rodger, A. S., Dudeney, J. R., Baker, K. B., Greenwald, R. A., and Greenspan, M.: Observations of an enhanced convection channel in the cusp ionosphere, J. Geophys. Res., 98, 3767-3776, 1993.

Pinnock, M., Rodger, A. S., Dudeney, J. R., Rich, F., and Baker, K. B.: High spatial and temporal resolution observations of the ionospheric cusps, Ann. Geophysicae, 13, 9190-925, 1995.

Provan, G. and Yeoman, T. K.: Statistical observations of the MLT, latitude and size of pulsed ionospheric flows with the CUTLASS Finland radar, Ann. Geophysicae, 17, 855-867, 1999.

Provan, G., Yeoman, T. K., and Milan, S. E.: CUTLASS Finland radar observations of the ionospheric signatures of flux transfer events and the resulting plasma flows, Ann. Geophysicae, 16, 1411-1422, 1998.

Rijnbeek, R. P., Cowley, S. W. H., Southwood, D. J., and Russell, C. T.: A survey of dayside flux transfer events observed by the ISEE-1 and -2 magnetometers, J. Geophys. Res., 89, 786-800, 1984.

Rishbeth, H. and van Eyken, A. P.: EISCAT: early history and the first ten years of operation, J. Atmos. Terr. Phys., 55, 525-542, 1993.
Rodger, A. S., Pinnock, M., Dudeney. J. R., Baker, K. B., and Greenwald, R. A.: A new mechansim for polar patch formation, J. Geophys. Res., 99, 6425-6436, 1994.

Ruohoniemi, J. M. and Baker, K. B.: Large-scale imaging of highlatitude convection with Super Dual Auroral Radar Network HF radar observations, J. Geophys. Res., 103, 20 797-20 811, 1998.

Ruohoniemi, J. M. and Greenwald, R. A.: Statistical patterns of high-latitude convection obtained from the Goose Bay HF radar observations, J. Geophys. Res., 101, 21 743-21 63, 1996.

Russell, C. T. and Elphic, R. C.: Initial ISEE magnetometer results: magnetopause observations, Space Science Review, 22, 681-715, 1978.

Russell, C. T. and Elphic, R. C.: ISEE observations of flux transfer events at the dayside magnetopause, Geophys. Res. Lett., 6, 3336, 1979.

Sandholt, P. E., Moen, J., and Opsvik, D.: Periodic auroral events at the midday polar cap boundary; implications for solar windmagnetosphere coupling, Geophys. Res. Lett., 19, 1223-1226, 1992.

Schiffler, A., Sofko, G., Newell, P. T., and Greenwald, R.: Mapping the outer LLBL with SuperDARN double-peaked spectra, Geophys. Res. Lett., 24, 3149-3152, 1997.

Schunk, R. W., Raitt, W. J., and Banks, P. M.: Effect of electric fields on the daytime high-latitude E- and F-regions, J. Geophys. Res., 80, 3121-3130, 1975.

Sojka, J. J., Bowline, M. D., Schunk, R. W., Decker, D. T., Valladares, C. E., Sheehan, R., Anderson, D. N., and Heelis, R. A.: Modelling polar cap F-region patches using time varying convection, Geophys. Res. Lett., 20, 1783-1786, 1993.

St-Maurice, J.-P. and Hanson, W. B.: Ion frictional heating at high latitudes and its possible use for an in situ determination of neutral thermospheric winds and temperatures, J. Geophys. Res., 87, 7580-7602, 1982.

St-Maurice, J.-P. and Schunk, R. W.: Ion velocity distributions in the high-latitude ionosphere, Rev. Geophys. Space Phys., 17, 99134, 1979.

Svalgaard, L.: Polar cap magnetic variations and their relationship with the interplanetary magnetic sector structure, J. Geophys. Res., 78, 2064-2078, 1973.

Tsunoda, R. T.: High-latitude F-region irregularities: a review and synthesis, Rev. Geophys., 26, 719-760, 1988.

van Eyken, A. P., Risbeth, H., Willis, D. M., and Cowley, S. W. H.: Initial observations of plasma convection at invariant latitudes of 70-77 , J. Atmos. Terr. Phys., 46, 635-641, 1984.

Weber, E. J., Buchau, J., Moore, J. G., Sharber, J. R., Livingston, R. C., Winningham, J. D., and Reinisch, B. W.: F-layer ionization patches in the polar cap, J. Geophys. Res., 89, 1683-1694, 1984.

Wild, J. A., Cowley, S. W. H., Davies, J. A., Khan, H., Lester, M., Milan, S. E., Provan, G., Yeoman, T. K., Balogh, A., Dunlop, M. W., Fornacon, K.-H., and Georgescu, E.: First simultaneous observations of flux transfer events at the high-latitude magnetopause by the Cluster spacecraft and pulsed radar signatures in the conjugate ionosphere by the CUTLASS and EISCAT radars, Ann. Geophysicae, 19, 1491-1508, 2001.

Yeoman, T. K., Lester, M., Cowley, S. W. H., Milan, S. E., Moen, J., and Sandholt, P. E.: Simultaneous observations of the cusp in optical, DMSP and HF radar data, Geophys. Res. Lett., 24, 2251-2254, 1997. 